\title{
Prevalence of metabolic syndrome and its associated factors in Chinese patients with ankylosing spondylitis
}

This article was published in the following Dove Press journal: Diabetes, Metabolic Syndrome and Obesity: Targets and Therapy

\author{
Meng Liu \\ Yukai Huang \\ Zhengping Huang \\ Qidang Huang \\ Xin Guo \\ Yunqing Wang \\ Weiming Deng \\ Zhixiang Huang \\ Tianwang $\mathrm{Li}$
}

Department of Rheumatology and Immunology, Guangdong Second Provincial General Hospital, Guangzhou, Guangdong, People's Republic of China

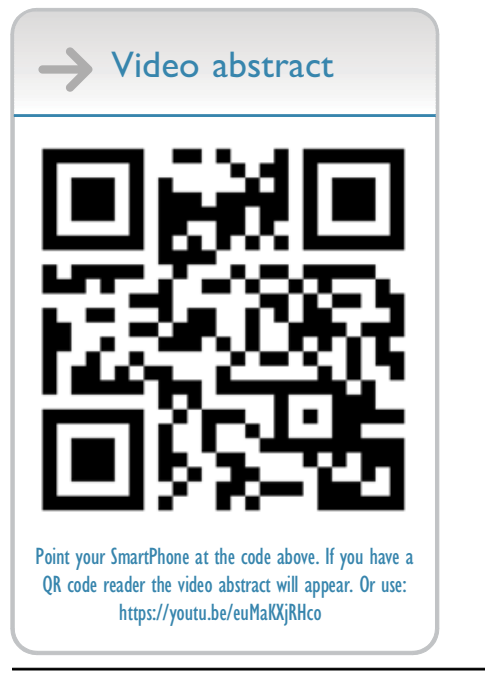

Correspondence: Tianwang $\mathrm{Li}$ Department of Rheumatology and Immunology, Guangdong Second Provincial General Hospital, No 466 Xingangzhonglu Road, Haizhu Square, Guangzhou, Guangdong 510220, People's Republic of China

Tel +862089169092

Fax +86 2089169092

Email |37I0874687@I63.com
Purpose: We assessed the prevalence of metabolic syndrome (MetS) and associated factors in mainland Chinese patients with ankylosing spondylitis (AS).

Patients and methods: A retrospective study was conducted in 117 AS patients and 117 age- and sex-matched healthy controls. Parameters of MetS based on the criteria established by the Chinese Diabetes Society in 2013 were tabulated. Demographic features, laboratory data, and clinical characteristics were also collected. Independent factors correlated with MetS in AS patients were identified by backward stepwise multivariate analysis.

Results: The prevalence of MetS was higher in AS patients than in healthy controls $(P=0.026)$. AS patients also had higher blood pressure and fasting serum glucose levels, but generally lower serum lipid levels. AS patients with and without MetS had no distinct differences in disease duration, medication usage, disease activity, or biomarkers of inflammation. Multivariable logistic regression analysis showed that hyperuricemia (odds ratio $[\mathrm{OR}]=2.385,95 \%$ confidence interval $[95 \% \mathrm{CI}]=1.019-5.582, P=0.045)$ and high body mass index $(\mathrm{BMI}, \mathrm{OR}=5.165 ; 95 \%$ $\mathrm{CI}=1.935-13.787, P=0.001)$ were independent factors for MetS in AS patients.

Conclusion: Chinese AS patients living in the mainland have an increased risk of developing MetS. Hyperuricemia and high BMI are predictors of MetS in AS patients.

Keywords: ankylosing spondylitis, metabolic syndrome, prevalence, hyperuricemia

\section{Introduction}

Ankylosing spondylitis (AS) is a chronic debilitating inflammatory autoimmune disease characterized by arthritis and tendinitis of the spine and peripheral joints. Patients with AS have increased mortality compared to the general population, despite improved management and prognoses in recent decades. ${ }^{1}$ Cardiovascular disease (CVD) has been confirmed as a crucial cause of mortality in AS patients. ${ }^{2}$ Rapidly accumulating evidence now verifies that there is a higher prevalence of cardiac pathology (ie, myocardial disease, valvular heart disease) and atherosclerosis in patients with $\mathrm{AS}^{3-5}$ Of note, studies have shown that AS-related systemic inflammation plays a vital role in the pathogenesis of CVD..$^{6-8}$

CVD risk factors such as obesity, insulin resistance, lipid disorders, and hypertension constitute a pathophysiological condition called metabolic syndrome (MetS). It is acknowledged that MetS increases the risk of CVD and associated mortality. ${ }^{9}$ Several studies have documented a higher prevalence of MetS in AS patients than in healthy subjects, ${ }^{10-13}$ but the factors leading to that finding are 
unknown. Given that few relevant studies of this problem have been done on the Chinese mainland, the present investigation was conducted to determine the prevalence of MetS in our Chinese AS patients living in the mainland and the possible determinants of its presence.

\section{Patients and methods}

\section{Patients and controls}

In this cross-sectional study, 117 AS patients who visited the Department of Rheumatology and Immunology at Guangdong Second Provincial General Hospital, Guangdong, China, from March 2016 and August 2018 were enrolled. The 117 consecutive patients met the modified New York criteria for the classification of $\mathrm{AS}^{14}$ but were excluded if they were $\leq 16$ years of age or had a history of acute myocardial infarction, stroke, coronary artery bypass, peripheral artery occlusive disease, transient ischemic attacks, or chronic kidney disease. The control group included 117 ageand gender-matched healthy subjects who were selected randomly from the Department of Physical Examination Center of Guangdong Second Provincial General Hospital in 2018. They had no specific chief complaints and no history of CVD. The study was approved by the research ethics committee of Guangdong Second Provincial General Hospital (2018FSKWZ-010), and all participants gave their informed written consent. Moreover, this study was conducted in accordance with the Declaration of Helsinki.

\section{Classification of MetS}

The criteria for MetS used in this study were those recommended by the Chinese Diabetes Society (CDS) in 2013, ${ }^{15}$ which were modified so as to be more appropriate for the Chinese population. MetS was defined when three or more of the following criteria were met: abdominal obesity (waist circumference (WC) $\geq 90 \mathrm{~cm}$ in men and $\geq 85 \mathrm{~cm}$ in women), fasting blood glucose (FBG) $\geq 6.1 \mathrm{mmol} / \mathrm{L}$ or on drug treatment for elevated glucose, elevated blood pressure $(\geq 130 / 85 \mathrm{mmHg}$ or on drug treatment for hypertension), fasting blood triglycerides (TG) $\geq 1.7 \mathrm{mmol} / \mathrm{L}$, and fasting blood high-density lipoprotein cholesterol (HDL-c) $<1.04 \mathrm{mmol} / \mathrm{L}$.

\section{Clinical evaluation and laboratory tests}

Demographic characteristics such as age, sex, height, weight, WC, smoking, and alcohol consumption habits were registered in all participants. Body mass index (BMI) was also calculated. According to the latest Chinese overweight/obesity medical nutrition treatment expert consensus (2016), ${ }^{16}$ overweight is defined as $24 \mathrm{~kg} / \mathrm{m}^{2} \leq \mathrm{BMI} \square 28 \mathrm{~kg} / \mathrm{m}^{2}$ and obesity is defined as BMI $\geq 28 \mathrm{~kg} / \mathrm{m}^{2}$. Hypertension and diabetes mellitus were evaluated. Blood pressure was measured based on the European Society of Hypertension guidelines. ${ }^{17}$

Clinical characteristics including disease duration, HLAB27 status, and medical therapies of AS patients were recorded. The Bath Ankylosing Disease Activity Index $(\mathrm{BASDAI})^{18}$ and Bath Ankylosing Spondylitis Functional Index $(\mathrm{BASFI})^{19}$ were further assessed. Additionally, venous blood samples were taken after an overnight fast (of at least 8 h) to measure FBG, total cholesterol (TC), TG, HDL-c, lowdensity lipoprotein cholesterol (LDL-c), serum uric acid (SUA), erythrocyte sedimentation rate (ESR), and C-reactive protein (CRP).

\section{Statistical analysis}

Continuous variables were described as mean values \pm standard deviation, and categorical variables were described as frequencies and percentages. The chi-square test or Fisher's exact test was used for categorical variables. For continuous variables, the Student's $t$-test was used for normally distributed values and the Mann-Whitney $U$ test was used for non-normally distributed values. To evaluate the predictors of incidental MetS in AS patients, a binary logistical regression model was used and odds ratios (OR) with $95 \%$ confidence interval $(95 \% \mathrm{CI})$ were calculated. The variables with $P \leq 0.1$ in univariate regression analyses were chosen for further backward stepwise regression analyses to identify the independent factors correlated with MetS in AS patients. A $P<0.05$ was considered significant, and all statistical analyses were carried out using SPSS software, version 20.0 (IBM Corp., Armonk, NY, USA).

\section{Results}

\section{Comparisons between AS patients and controls}

The comparisons of demographic characteristics, blood pressure, and laboratory measurements between AS patients and controls are listed in Table 1. These two groups were similar with regard to age, gender, BMI, overweight/obesity, LDL-c, and SUA. The AS group showed higher systolic blood pressure $(119.9 \pm 11.5 \mathrm{vs} 113.2 \pm 12 \mathrm{mmHg} ; P<0.001)$, diastolic blood pressure ( $74.6 \pm 7.9$ vs $71.2 \pm 9.9 \mathrm{mmHg} ; P<0.001)$, TC/HDL-c $(3.9 \pm 0.8$ vs $3.5 \pm 0.5 ; P<0.001)$, and FBG $(5.0 \pm 1.0$ vs $4.9 \pm 1.6 \mathrm{mmol} / \mathrm{L} ; P=0.004)$ and lower TC ( 4.2 \pm 0.9 vs $4.8 \pm 0.9 \mathrm{mmol} / \mathrm{L} ; P<0.001)$, HDL-c $(1.1 \pm 0.2$ vs 
Table I Comparison of the patients with ankylosing spondylitis and the controls

\begin{tabular}{|c|c|c|c|}
\hline Variables & $\begin{array}{l}\text { AS } \\
\text { patients } \\
(n=1 \mid 7)\end{array}$ & $\begin{array}{l}\text { Controls } \\
(n=1 \mid 7)\end{array}$ & $P$-value \\
\hline Age (years) & $35 \pm 10.3$ & $35.4 \pm 9.5$ & 0.726 \\
\hline Sex (male/female) & $97 / 20$ & $92 / 25$ & 0.407 \\
\hline $\begin{array}{l}\text { Metabolic syndrome, } \\
n(\%)\end{array}$ & $23(19.7)$ & II (9.4) & 0.026 \\
\hline $\begin{array}{l}\text { Overweight/obesity, } \\
n(\%)\end{array}$ & $47(40.2)$ & $41(35.0)$ & 0.418 \\
\hline $\begin{array}{l}\text { Body mass index } \\
\left(\mathrm{kg} / \mathrm{m}^{2}\right)\end{array}$ & $22.9 \pm 3.9$ & $22.7 \pm 3.0$ & 0.986 \\
\hline $\begin{array}{l}\text { Systolic blood pressure } \\
(\mathrm{mmHg})\end{array}$ & $119.9 \pm 11.5$ & $113.2 \pm 12$ & 0.000 \\
\hline $\begin{array}{l}\text { Diastolic blood pressure } \\
(\mathrm{mmHg})\end{array}$ & $74.6 \pm 7.9$ & $71.2 \pm 9.9$ & 0.000 \\
\hline $\begin{array}{l}\text { Fasting blood glucose } \\
(\mathrm{mmol} / \mathrm{L})\end{array}$ & $5.0 \pm 1.0$ & $4.9 \pm 1.6$ & 0.004 \\
\hline \multicolumn{4}{|l|}{ Lipid profile (mmol/L) } \\
\hline $\mathrm{TC}$ & $4.2 \pm 0.9$ & $4.8 \pm 0.9$ & 0.000 \\
\hline HDL-c & $1.1 \pm 0.2$ & $1.4 \pm 0.3$ & 0.000 \\
\hline Low-density lipoprotein & $2.4 \pm 0.7$ & $2.6 \pm 0.7$ & 0.134 \\
\hline Triglycerides & I. $2 \pm 0.9$ & $1.7 \pm 2.3$ & 0.000 \\
\hline TC/HDL-c & $3.9 \pm 0.8$ & $3.5 \pm 0.5$ & 0.000 \\
\hline $\begin{array}{l}\text { Serum uric acid } \\
(\mu \mathrm{mol} / \mathrm{L})\end{array}$ & $380.6 \pm 95.1$ & $393.5 \pm 92.5$ & 0.336 \\
\hline
\end{tabular}

Abbreviations: AS, ankylosing spondylitis; TC, total cholesterol; HDL-c, highdensity lipoprotein.

$1.4 \pm 0.3 \mathrm{mmol} / \mathrm{L} ; P<0.001)$ and TG $(1.2 \pm 0.9$ vs $1.7 \pm 2.3$ $\mathrm{mmol} / \mathrm{L} ; P<0.001)$ than controls. Finally, the AS patients had a higher prevalence of MetS than controls $(19.7 \%$ vs $9.4 \% ; P=0.026)$ using the $2013 \mathrm{CDS}$ criteria.

\section{Comparison of all MetS subjects}

Table 2 summarizes the characteristics of the MetS in AS patients and the controls. TC $(4.6 \pm 0.9$ vs $5.3 \pm 1.6 \mathrm{mmol} /$ $\mathrm{L} ; P=0.032)$ and HDL-c $(1.4 \pm 0.1$ vs $1.6 \pm 0.7 \mathrm{mmol} / \mathrm{L}$; $P=0.002)$ were lower in AS MetS patients relative to the controls while the ratio of TC/HDL-c $(4.4 \pm 0.9$ vs $3.7 \pm$ $0.6 ; P=0.018$ ) was higher in AS MetS patients compared to the controls. No significant differences were found in age, sex, BMI, obesity, WC, blood pressure, FBG, LDL-c,
Table 2 Comparison of metabolic syndrome in ankylosing spondylitis patients and controls

\begin{tabular}{|c|c|c|c|}
\hline Variables & $\begin{array}{l}\text { AS patients } \\
(n=23)\end{array}$ & $\begin{array}{l}\text { Controls } \\
(n=I I)\end{array}$ & $P$-value \\
\hline Age (years) & $38.6 \pm 9.6$ & $41 \pm 8.9$ & 0.490 \\
\hline Sex (male/female) & $20 / 3$ & $9 / 2$ & 1.0 \\
\hline Obesity, nn (\%) & $10(43.5)$ & $2(18.2)$ & 0.289 \\
\hline $\begin{array}{l}\text { Body mass index }(\mathrm{kg} / \\
\left.\mathrm{m}^{2}\right)\end{array}$ & $26.8 \pm 4$ & $24.6 \pm 2.4$ & 0.098 \\
\hline WC abnormal, n (\%) & $20(87.0)$ & $9(81.8)$ & 1.0 \\
\hline $\begin{array}{l}\text { Systolic blood pres- } \\
\text { sure }(\mathrm{mmHg})\end{array}$ & $128.1 \pm 12.5$ & $122.5 \pm 17.5$ & 0.285 \\
\hline $\begin{array}{l}\text { Diastolic blood pres- } \\
\text { sure }(\mathrm{mmHg})\end{array}$ & $78.4 \pm 8.2$ & $85.2 \pm 13.7$ & 0.08 \\
\hline $\begin{array}{l}\text { Fasting blood glucose } \\
(\mathrm{mmol} / \mathrm{L})\end{array}$ & $5.8 \pm 1.7$ & $7.3 \pm 4.4$ & 0.772 \\
\hline \multicolumn{4}{|l|}{ Lipid profile (mmol/L) } \\
\hline TC & $4.6 \pm 0.9$ & $5.3 \pm 1.6$ & 0.032 \\
\hline HDL-c & $\mathrm{I} .4 \pm 0 . \mathrm{I}$ & $1.6 \pm 0.7$ & 0.002 \\
\hline $\begin{array}{l}\text { Low-density } \\
\text { lipoprotein }\end{array}$ & $2.7 \pm 0.3$ & $3.1 \pm 1.0$ & 0.186 \\
\hline Triglycerides & $2.1 \pm 1.3$ & $1.9 \pm 0.4$ & 1.0 \\
\hline TC/HDL-C & $4.4 \pm 0.9$ & $3.7 \pm 0.6$ & 0.018 \\
\hline $\begin{array}{l}\text { Serum uric acid } \\
(\mu \mathrm{mol} / \mathrm{L})\end{array}$ & $405.2 \pm 81.4$ & $\begin{array}{l}434.2 \pm \\
101.2\end{array}$ & 0.375 \\
\hline
\end{tabular}

Abbreviations: AS, ankylosing spondylitis; WC, waist circumference; TC, total cholesterol; HDL-c, high-density lipoprotein.

TG, or SUA between the MetS in AS patients and the controls.

\section{Comparisons between the AS patients with and without MetS}

Table 3 compares the MetS AS patients vs non-MetS AS patients. AS patients with MetS showed higher frequencies of hypertension $(26.1 \%$ vs $3.2 \% ; P=0.001)$, diabetes $(13 \%$ vs $1.1 \% ; P=0.024)$, and overweight/obesity $(78.3 \%$ vs $31.9 \% ; P<0.001)$. Moreover, BMI, blood pressure, FBG, $\mathrm{TC}, \mathrm{TG}$, and the ratio of TC/HDL-c were significantly higher in AS MetS patients relative to non-MetS patients (all $P<0.05$ ). Interestingly, BASFI was lower in AS MetS patients compared with non-MetS patients $(9.2 \pm 18.3$ vs $17.4 \pm 22.5 ; P=0.043)$. No significant differences were 
Table 3 Characteristics of ankylosing spondylitis patients, with and without metabolic syndrome

\begin{tabular}{|c|c|c|c|}
\hline \multirow[t]{2}{*}{ Variables } & \multicolumn{2}{|c|}{ Metabolic syndrome } & \multirow[t]{2}{*}{$P$-value } \\
\hline & Yes $(n=23)$ & No $(n=94)$ & \\
\hline Age (years) & $38.6 \pm 9.6$ & $34.2 \pm 10.3$ & 0.068 \\
\hline Sex (male/female) & $20 / 3$ & $77 / 17$ & 0.790 \\
\hline Smoking, n (\%) & $\mathrm{I}(4.3)$ & $22(23.4)$ & 0.077 \\
\hline Drinking, n (\%) & I (4.3) & $2(2.1)$ & 0.485 \\
\hline Disease duration (months) & $134.8 \pm 91.6$ & $100.5 \pm 83.8$ & 0.073 \\
\hline Hypertension, n (\%) & $6(26.1)$ & $3(3.2)$ & 0.001 \\
\hline Diabetes, n (\%) & $3(13.0)$ & $\mathrm{I}(\mathrm{I} . \mathrm{I})$ & 0.024 \\
\hline Overweight/obesity, n (\%) & $18(78.3)$ & $30(31.9)$ & 0.000 \\
\hline Body mass index & $26.8 \pm 4.0$ & $22.0 \pm 3.3$ & 0.000 \\
\hline Systolic blood pressure $(\mathrm{mmHg})$ & $128.1 \pm 12.5$ & $117.8 \pm 10.4$ & 0.001 \\
\hline Diastolic blood pressure $(\mathrm{mmHg})$ & $78.4 \pm 8.2$ & $73.7 \pm 7.6$ & 0.01 \\
\hline Fasting blood glucose (mmol/L) & $5.8 \pm 1.7$ & $4.8 \pm 0.7$ & 0.000 \\
\hline \multicolumn{4}{|l|}{ Lipid profile (mmol/L) } \\
\hline TC & $4.6 \pm 0.9$ & $4.1 \pm 0.8$ & 0.015 \\
\hline HDL-c & $1.04 \pm 0.1$ & $\mathrm{I} . \mathrm{I} \pm 0.3$ & 0.363 \\
\hline Low-density lipoprotein & $2.7 \pm 0.6$ & $2.4 \pm 0.7$ & 0.054 \\
\hline Triglycerides & $2.1 \pm 1.3$ & $1.0 \pm 0.5$ & 0.000 \\
\hline TC/HDL-c & $4.4 \pm 0.9$ & $3.8 \pm 0.8$ & 0.000 \\
\hline Serum uric acid $(\mu \mathrm{mol} / \mathrm{L})$ & $405.2 \pm 81.4$ & $368.3 \pm 94.8$ & 0.089 \\
\hline CRP (mg/L) & $12.1 \pm 14.3$ & $21.2 \pm 25.9$ & 0.106 \\
\hline $\mathrm{ESR}(\mathrm{mm} / \mathrm{h})$ & $25.6 \pm 20.1$ & $31.8 \pm 27.2$ & 0.405 \\
\hline HLA-B27 positivity, n (\%) & $21(91.3)$ & $79(84.0)$ & 0.729 \\
\hline BASDAI & $2.3 \pm 2.4$ & $2.9 \pm 2.0$ & 0.137 \\
\hline BASFI & $9.2 \pm 18.3$ & $17.4 \pm 22.5$ & 0.043 \\
\hline \multicolumn{4}{|l|}{ Medications, n (\%) } \\
\hline TNF-i & $18(78.3)$ & $57(60.6)$ & 0.114 \\
\hline DMARDs & $18(78.3)$ & $62(66.0)$ & 0.255 \\
\hline NSAIDs & $21(91.3)$ & $93(100)$ & 0.098 \\
\hline Prednisone & $0(0)$ & $10(10.6)$ & 0.223 \\
\hline
\end{tabular}

Abbreviations: TC, total cholesterol; HDL-c, high-density lipoprotein; CRP, C-reactive protein; ESR, erythrocyte sedimentation rate; HLA-B27, human leukocyte antigenB27; BASDAI, Bath Ankylosing Disease Activity Index; BASFI, Bath Ankylosing Spondylitis Functional Index; TNF-i, tumor necrosis factor inhibitors; DMARDs, diseasemodifying anti-rheumatic drugs; NSAIDs, non-steroidal anti-inflammatory drugs. 
Table 4 Univariate regression analyses and multivariate regression analyses of variables associated with metabolic syndrome in patients with ankylosing spondylitis

\begin{tabular}{|c|c|c|c|c|c|c|}
\hline \multirow[t]{2}{*}{ Predictors } & \multicolumn{3}{|c|}{ Univariate regression analyses } & \multicolumn{3}{|c|}{ Multivariate regression analyses } \\
\hline & $\beta$ & OR (95\%Cl) & $P$-value & $\beta$ & OR $(95 \% \mathrm{Cl})$ & $P$-value \\
\hline Age & 0.041 & $1.04 \mid(0.996-1.088)$ & 0.071 & - & - & - \\
\hline Sex & 0.387 & $1.472(0.392-5.522)$ & 0.567 & & & \\
\hline BMI & 0.378 & $1.459(1.229-1.733)$ & 0.000 & 1.642 & $5.165(1.935-13.787)$ & 0.001 \\
\hline TC/HDL-C & 0.875 & $2.400(1.348-4.274)$ & 0.003 & - & - & - \\
\hline SUA & 0.004 & $1.004(0.999-1.009)$ & 0.094 & 0.869 & $2.385(1.019-5.582)$ & 0.045 \\
\hline CRP & -0.024 & $0.976(0.947-1.006)$ & 0.117 & & & \\
\hline ESR & -0.011 & $0.989(0.969-1.010)$ & 0.305 & & & \\
\hline Disease duration & 0.004 & 1.004 (0.999-1.009) & 0.092 & - & - & - \\
\hline BASDAI & -0.149 & $0.86 \mid(0.675-1.099)$ & 0.229 & & & \\
\hline BASFI & -0.023 & $0.977(0.948-1.007)$ & 0.137 & & & \\
\hline TNF-i & 0.849 & $2.337(0.799-6.838)$ & 0.121 & & & \\
\hline DMARDs & 0.620 & $1.858(0.632-5.465)$ & 0.260 & & & \\
\hline NSAIDs & -2.181 & $0.113(0.010-1.304)$ & 0.081 & - & - & - \\
\hline
\end{tabular}

Abbreviations: BMI, body mass index; TC, total cholesterol; HDL-c, high-density lipoprotein; SUA, serum uric acid; CRP, C-reactive protein; ESR, erythrocyte sedimentation rate; BASDAI, Bath Ankylosing Disease Activity Index; BASFI, Bath Ankylosing Spondylitis Functional Index; TNF-i, tumor necrosis factor inhibitors; DMARDs, disease-modifying anti-rheumatic drugs; NSAIDs, non-steroidal anti-inflammatory drugs.

observed in age, gender, smoking, drinking, disease duration, LDL-c, HDL-c, SUA, CRP, ESR, the positivity of HLA-B27, and BASDAI. Furthermore, the prescription rates for tumor necrosis factor inhibitors (TNF-i), diseasemodifying anti-rheumatic drugs, non-steroidal antiinflammatory drugs, and prednisone were also similar in the two groups.

\section{Associated factors of MetS in AS}

Table 4 summarizes the results of the logistic regression analyses. As there were only 0 or 1 patient with histories of smoking, drinking, or prednisone treatment in the MetSAS group, apart from the components of MetS, those three variables were eliminated from the univariate analyses to avoid selection bias. In the univariate analyses, age, BMI, the ratio of TC/HDL-c, SUA, disease duration, and NSAID usage were identified as being different between the MetS AS patients and the non-MetS AS patients with $P \leq 0.1$, and therefore these variables were included in the multivariate regression analysis. Finally, two important predictors of MetS in AS patients were verified: SUA $(\mathrm{OR}=2.385 ; 95 \% \mathrm{CI}=1.019-5.582 ; P=0.045)$ and high $\mathrm{BMI}(\mathrm{OR}=5.165 ; 95 \% \quad \mathrm{CI}=1.935-13.787$; $P=0.001$ ) (Table 4).

\section{Discussion}

The present study confirmed that mainland Chinese AS patients had a higher prevalence of MetS than the general population. Furthermore, we verified that SUA and high BMI were independent predictors of MetS in these Chinese AS patients.

According to the 2013 CDS criteria, this study found that MetS occurred in $19.7 \%$ of the AS patients as compared with $9.4 \%$ of the healthy individuals. Previous studies also investigated the prevalence of MetS in AS patients and found rates of $45.8 \%$ in Italy, ${ }^{10} 34.9 \%$ in Greece, ${ }^{11}$ and $27 \%$ in Brazil. ${ }^{13}$ Our study found a lower prevalence of MetS in Chinese AS patients than that indicated in foreign reports. This difference may result from the younger age of the AS patients in our study (35 vs 40-50.5 years) or the different criteria of MetS since the 2013 CDS criteria were developed to specifically define MetS for the Chinese. Different therapeutic strategies, genetic factors, and races should also be considered. However, the results of our study indicating that MetS was 
more prevalent in AS patients than in the controls was in agreement with previous studies. ${ }^{10-13}$

AS patients in this study had lower HDL-c and TC levels but higher TC/HDL-c ratios than the controls. AS patients with MetS also had lower HDL-c and TC but higher TC/ HDL-c ratios than the healthy controls with MetS. HDL-c has anti-inflammatory and anti-atherosclerotic properties. ${ }^{20}$ Mathieu et al reported that decreased TC and HDL-c occurred in AS patients and that the low HDL-c levels appeared to play a crucial role in developing myocardial infarctions in AS patients. ${ }^{21}$ Moreover, Toms et al found that TC/HDL-c had a better association with inflammatory biomarkers and CVD risk than TC or HDL-c in patients with rheumatoid arthritis. ${ }^{22}$ Therefore, we further tested whether TC/HDL-c was an independent predictor of MetS in AS patients. In the univariate regression analyses, TC/HDL-c significantly increased the danger of MetS in AS patients $(\mathrm{OR}=2.400 ; 95 \% \mathrm{CI}=1.348-4.274 ; P=0.003)$. However, this ratio was removed from the analysis after adjustment with other factors. As an index for predicting the cardiac risk, TC/HDL-c in AS patients with MetS has an uncertain role and will need further investigation to establish its usefulness.

In this study, SUA levels showed no difference between MetS and non-MetS in AS patients, which was in keeping with the results of Maia et $\mathrm{al}^{13}$. Nevertheless, SUA was associated with AS MetS patients under the univariate regression analyses $(P \leq 0.1)$. The cut point of SUA in the further multivariate regression analysis was $416.4 \mu \mathrm{mol} / \mathrm{L}$ for men and $356.9 \mu \mathrm{mol} / \mathrm{L}$ for women, which means that hyperuricemia independently increased the risk of MetS in AS patients $(\mathrm{OR}=2.385 ; 95 \% \mathrm{CI}=1.019-5.582 ; P=$ 0.045 ). Lin et $\mathrm{al}^{23}$ reported that hyperuricemia was strongly correlated with the development of MetS in subjects in Taiwan. The possible common mechanisms underlying the development of hyperuricemia and MetS were also identified: endothelial damage via oxidativeredox stress, systemic inflammation, adipokines (such as leptin), unhealthy diets, and lack of physical activity. ${ }^{23}$ Additionally, studies have demonstrated that people with hyperuricemia had a higher risk of developing hypertension, overweight/obesity, type 2 diabetes mellitus, kidney diseases, and CVD. ${ }^{24}$ Recently, Zhu et $\mathrm{al}^{25}$ found that without concomitant gout, significant deposition of monosodium urate crystals occurred in the sacroiliac joint of patients with axial spondyloarthropathy and exacerbated the radiographic progression of their disease. Thus, the current evidence suggests that hyperuricemia cannot be ignored in AS patients.

We found that BASDAI, CRP, ESR, and disease duration were not different in the MetS and non-MetS AS patients, which was consistent with both Malesci's ${ }^{10}$ and Maia's ${ }^{13}$ reports, while Papadakis et al $^{11}$ found that MetS AS patients had higher BASDAI $(P<0.05)$ and longer disease duration $(P<0.05)$. In addition, non-MetS AS patients in our study showed significantly higher BASFI indices than the MetS AS patients $(P=0.043)$, while the univariate regression analyses were not different $(P=0.137)$. Previous studies also showed no difference of BASFI between the two groups, ${ }^{10-13}$ and so our results support the idea that BASFI has no bearing on MetS in AS patients.

The stepwise multivariate regression analysis in our study also suggested that high BMI independently increases the prevalence of MetS in AS patients $(\mathrm{OR}=$ 5.165; 95\% CI $=1.935-13.787 ; P=0.001)$. Moreover, high BMI has been reported to be a crucial determinant MetS in rheumatoid arthritis, ${ }^{26}$ systemic lupus erythematosus, ${ }^{27}$ and psoriasis. ${ }^{28}$ The mechanisms for accelerating MetS by high BMI have also been explored: more proinflammatory cytokines (including TNF- $\alpha$ and IL-6) and adipokines (such as leptin and adiponectin) are released by fat tissue, which adversely affect MetS. ${ }^{29}$

As the present report is the first study concerning the prevalence of MetS in mainland Chinese AS patients, some limitations should be mentioned. First, socioeconomic factors such as educational attainment, field of employment, and poverty level were not taken into account. These factors may also affect the prevalence of MetS. Second, a cross-sectional study design might not be useful to determine causality between AS and presence of MetS. Third, this was a single-center study; thus, its reliability and representativeness were open to question.

\section{Conclusion}

This study showed a greater prevalence of MetS in mainland Chinese AS patients than controls. AS patients with hyperuricemia or/and high BMI are more susceptible to MetS. Our study indicates that, beyond traditional CVD risk factors, special attention should be paid to effective control of SUA for preventing MetS in AS patients.

\section{Acknowledgments}

This study was supported by Natural Science Foundation of Guangdong Province (No. 2017A030313526) and 
Youth Foundation of Guangdong Second Provincial General Hospital (No. YQ2017-009).

\section{Disclosure}

The authors report no conflicts of interest in this work.

\section{References}

1. Bakland G, Gran JT, Nossent JC. Increased mortality in ankylosing spondylitis is related to disease activity. Ann Rheum Dis. 2011;70 (11):1921-1925. doi:10.1136/ard.2011.151191

2. Szabo SM, Levy AR, Rao SR, et al. Increased risk of cardiovascular and cerebrovascular diseases in individuals with ankylosing spondylitis: a population-based study. Arthritis Rheum. 2011;63(11):3294-3304. doi:10.1002/art.30581

3. Heslinga SC, Van Dongen CJ, Konings TC, et al. Diastolic left ventricular dysfunction in ankylosing spondylitis-a systematic review and meta-analysis. Semin Arthritis Rheum. 2014;44(1):14-19. doi:10.1016/j.semarthrit.2014.02.004

4. Mathieu S, Pereira B, Soubrier M. Cardiovascular events in ankylosing spondylitis: an updated meta-analysis. Semin Arthritis Rheum. 2015;44(5):551-555. doi:10.1016/j.semarthrit. 2014.10.007

5. Midtbo H, Gerdts E, Berg IJ, Rollefstad S, Jonsson R, Semb AG. Ankylosing Spondylitis Is Associated with Increased Prevalence of Left Ventricular Hypertrophy. J Rheumatol. 2018;45(9):1249-1255. doi:10.3899/jrheum.171124

6. Piepoli MF, Hoes AW, Agewall S, et al. 2016 European Guidelines on cardiovascular disease prevention in clinical practice: the Sixth Joint Task Force of the European Society of Cardiology and Other Societies on Cardiovascular Disease Prevention in Clinical Practice (constituted by representatives of 10 societies and by invited experts) Developed with the special contribution of the European Association for Cardiovascular Prevention \& Rehabilitation (EACPR). Eur Heart J. 2016;37 (29):2315-2381. doi:10.1093/eurheartj/ehw106

7. Semb AG, Ikdahl E, Hisdal J, Olsen IC, Rollefstad S. Exploring cardiovascular disease risk evaluation in patients with inflammatory joint diseases. Int $J$ Cardiol. 2016;223:331-336. doi:10.1016/j. ijcard.2016.08.129

8. Agca R, Heslinga SC, Rollefstad S, et al. EULAR recommendations for cardiovascular disease risk management in patients with rheumatoid arthritis and other forms of inflammatory joint disorders: 2015/ 2016 update. Ann Rheum Dis. 2017;76(1):17-28. doi:10.1136/ annrheumdis-2016-209775

9. Hess PL, Al-Khalidi HR, Friedman DJ, et al. The metabolic syndrome and risk of sudden cardiac death: the atherosclerosis risk in communities study. J Am Heart Assoc. 2017;6(8). doi:10.1161/ JAHA. 117.006103

10. Malesci D, Niglio A, Mennillo GA, Buono R, Valentini G, La Montagna G. High prevalence of metabolic syndrome in patients with ankylosing spondylitis. Clin Rheumatol. 2007;26(5):710-714. doi:10.1007/s10067-006-0380-5

11. Papadakis JA, Sidiropoulos PI, Karvounaris SA, et al. High prevalence of metabolic syndrome and cardiovascular risk factors in men with ankylosing spondylitis on anti-TNF-alpha treatment: correlation with disease activity. Clin Exp Rheumatol. 2009;27 (2):292-298.

12. Mok CC, Ko GT, Ho LY, Yu KL, Chan PT, To CH. Prevalence of atherosclerotic risk factors and the metabolic syndrome in patients with chronic inflammatory arthritis. Arthritis Care Res (Hoboken). 2011;63(2):195-202. doi:10.1002/acr.20363
13. Maia DG, Augusto KL, Bezerra MC, Rodrigues CEM. Metabolic syndrome in patients with ankylosing spondylitis receiving anti-TNFalpha therapy: association with predictors of cardiovascular risk. Clin Rheumatol. 2017;36(10):2371-2376. doi:10.1007/s10067-017-3623-8

14. van der Linden S, Valkenburg HA, Cats A. Evaluation of diagnostic criteria for ankylosing spondylitis. a proposal for modification of the New York criteria. Arthritis Rheum. 1984;27(4):361-368.

15. Chinese Diabetes Society. China Guideline for Type 2 Diabetes: 2013 update. Chin J Diabetes Mellitus. 2014;7(6):447-498.

16. Chinese overweight/obesity expert consensus committee on medical nutrition therapy. China overweight/obesity medical nutrition treatment expert consensus (2016 edition). Chin J Diabetes Mellitus. 2016;8(9):525-540.

17. Mancia G, Fagard R, Narkiewicz K, et al. 2013 ESH/ESC practice guidelines for the management of arterial hypertension. Blood Press. 2014;23(1):3-16. doi:10.3109/08037051.2014.868629

18. Garrett S, Jenkinson T, Kennedy LG, Whitelock H, Gaisford P, Calin A. A new approach to defining disease status in ankylosing spondylitis: the Bath Ankylosing Spondylitis Disease Activity Index. J Rheumatol. 1994;21(12):2286-2291.

19. Calin A, Garrett S, Whitelock H, et al. A new approach to defining functional ability in ankylosing spondylitis: the development of the Bath Ankylosing Spondylitis Functional Index. J Rheumatol. 1994;21 (12):2281-2285.

20. Davidson MH, Toth PP. High-density lipoprotein metabolism: potential therapeutic targets. Am J Cardiol. 2007;100(11A):n32-40. doi:10.1016/j.amjcard.2007.08.011

21. Mathieu S, Gossec L, Dougados M, Soubrier M. Cardiovascular profile in ankylosing spondylitis: a systematic review and meta-analysis. Arthritis Care Res (Hoboken). 2011;63(4):557-563. doi:10.1002/acr.20364

22. Toms TE, Panoulas VF, Douglas KM, et al. Are lipid ratios less susceptible to change with systemic inflammation than individual lipid components in patients with rheumatoid arthritis? Angiology. 2011;62(2):167-175. doi:10.1177/0003319710373749

23. Lin WY, Liu CS, Li TC, et al. In addition to insulin resistance and obesity, hyperuricemia is strongly associated with metabolic syndrome using different definitions in Chinese populations: a population-based study (Taichung Community Health Study). Ann Rheum Dis. 2008;67(3):432-433. doi:10.1136/ard.2007.073601

24. Madsen TE, Muhlestein JB, Carlquist JF, et al. Serum uric acid independently predicts mortality in patients with significant, angiographically defined coronary disease. Am J Nephrol. 2005;25 (1):45-49. doi:10.1159/000084085

25. Zhu J, Li A, Jia E, et al. Monosodium urate crystal deposition associated with the progress of radiographic grade at the sacroiliac joint in axial SpA: a dual-energy CT study. Arthritis Res Ther. 2017;19(1):83. doi:10.1186/s13075-017-1286-0

26. Tantayakom P, Koolvisoot A, Arromdee E, Chiowchanwisawakit P, Muangchan C, Katchamart W. Metabolic syndrome is associated with disease activity in patients with rheumatoid arthritis. Joint Bone Spine. 2016;83(5):563-567. doi:10.1016/j.jbspin.2015.10.016

27. Fatemi A, Ghanbarian A, Sayedbonakdar Z, Kazemi M, Smiley A. Metabolic syndrome in Iranian patients with systemic lupus erythematosus and its determinants. Clin Rheumatol. 2018;37 (6):1521-1528. doi:10.1007/s10067-017-3970-5

28. Caso F, Del Puente A, Oliviero F, et al. Metabolic syndrome in psoriatic arthritis: the interplay with cutaneous involvement. Evidences from literature and a recent cross-sectional study. Clin Rheumatol. 2018;37(3):579-586. doi:10.1007/s10067-017-3975-0

29. Medina G, Vera-Lastra O, Peralta-Amaro AL, et al. Metabolic syndrome, autoimmunity and rheumatic diseases. Pharmacol Res. 2018;133:277-288. doi:10.1016/j.phrs.2018.01.009 


\section{Publish your work in this journal}

Diabetes, Metabolic Syndrome and Obesity: Targets and Therapy is an international, peer-reviewed open-access journal committed to the rapid publication of the latest laboratory and clinical findings in the fields of diabetes, metabolic syndrome and obesity research. Original research, review, case reports, hypothesis formation, expert opinion and commentaries are all considered for publication. The manuscript management system is completely online and includes a very quick and fair peer-review system, which is all easy to use. Visit http://www.dovepress.com/testimonials.php to read real quotes from published authors.

Submit your manuscript here: https://www.dovepress.com/diabetes-metabolic-syndrome-and-obesity-targets-and-therapy-journal 